\section{Pesticides alter bee foraging}

Bumblebees that have been exposed to neonicotinoid pesticides are slower to learn how best to collect pollen from wildflowers than are their unexposed counterparts.

Neonicotinoids are widely used insecticides, and their application has been restricted in some countries because of their negative impact on bees. To study the effects of the chemicals on bee foraging, Dara Stanley at Royal Holloway University of London in Egham, UK, and Nigel Raine at the University of Guelph, Canada, observed individual bumblebees

(Bombus terrestris) while the insects foraged on two species of wildflower. Bee colonies that had been dosed with the neonicotinoid thiamethoxam released more foragers, and these bees collected pollen more often than did controls. But unexposed bees required fewer visits to flowers to learn how to collect pollen efficiently.

The results suggest that environmental exposure to this insecticide at sub-lethal levels probably changes how well bees forage and pollinate in the wild, say the authors. Funct. Ecol. http://doi.org/bdn8 (2016)

\section{GENETICS}

\section{Feathery feet are more like wings}

Some bird feet are covered by feathers (pictured) instead of scales and show greater similarity to wings than to legs at the molecular level.

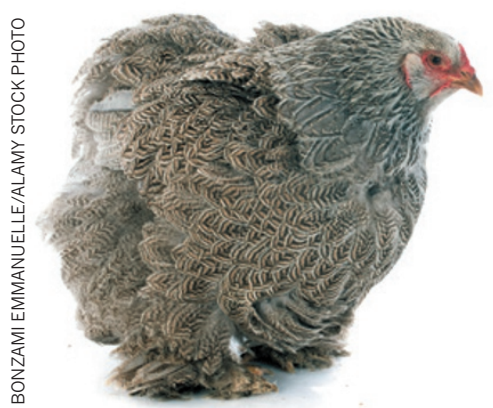

Michael Shapiro at the University of Utah in Salt Lake City and his colleagues crossed breeds of domestic pigeon (Columba livia) that had feathery or scaly feet and analysed the offspring to identify genomic regions that contribute to this unusual trait. They also compared the genomes of 15 featherfooted and 28 scale-footed pigeons.

They found that the hind limbs of birds with feathery feet showed gene-expression patterns that resembled those of wings, or fore limbs. In pigeon and chicken embryos, a gene called $T b \times 5$ that normally regulates forelimb outgrowth and identity was expressed in the developing legs of birds with feathery feet. Furthermore, the expression of Pitx 1, a hindlimb gene, was lower in these birds than in those with scaly feet.

eLife 5, e12115 (2016)

Warm weather
sets rocks loose

Rockfalls in steep terrain could be triggered by warm weather.

Precipitation, earthquakes and freeze-thaw cycles are known to increase the risk of rockfalls, but some falls have no known cause. Brian Collins of the US Geological Survey in Menlo Park, California, and Greg Stock of the US National Park Service in El Portal, California, attached 'crackmeters' to a 500-metre cliff in California's Yosemite National Park.

They found that a crack behind a slab in the cliff widened every day as the rock expanded in the heat, and closed up at night. It was also wider during the summer than in the winter. Over 3.5 years, the crack steadily opened up, and the authors say that such rock slabs could eventually fall, even without stresses such as an earthquake or heavy rain.

The study suggests that warm summer afternoons are most likely to see such

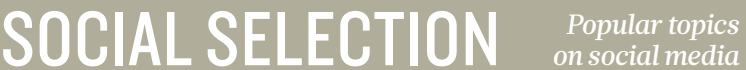

\section{Mammals face off in Twitter battle}

While US basketball fans nationwide have been cheering on Badgers and Wildcats in the NCAA college-level tournament this month, scientists and animal enthusiasts have been riveted by pandas, bison and other furry combatants in Mammal March Madness. The Twitter-based competition, organized by four biologists, features hypothetical battles that are based on the real-life strengths and vulnerabilities of the contestants. In the final battle on $24 \mathrm{March}$, the tundra wolf defeated the forest hog. Since its debut in 2013, the month-long tournament has attracted a passionate base of fans who try to predict the results of each round and root for their favourite animals, while discussing online the biology of the mammals. Laura Huenneke, an ecologist at Northern Arizona University in Flagstaff, summed up the drama on Twitter: "Unlike NCAA, DNATURE.COM March Mammal Madness \#2016MMM For more on has equal appeal for 3 yr olds, pro popular papers: $\quad$ biologists...unbearable cuteness AND go.nature.com/cg6cxf total geek curiosity."

rockfalls, which matches records at Yosemite and other places around the world. Nature Geosci. http://dx.doi. org/10.1038/ngeo2686 (2016)

\section{ANTHROPOLOGY}

\section{Ancient genomes from tooth plaque}

Hardened plaque from 700-year-old teeth has yielded complete mitochondrial genomes for six people.

Calcified dental plaque, or calculus, is often preserved on ancient teeth, and studies have identified human and bacterial proteins in the build-up. A team led by Christina Warinner at the University of Oklahoma in Norman sequenced DNA in the calculus on 700-year-old remains from a cemetery in Illinois. The samples contained enough DNA to reconstruct full mitochondrial genomes.

The calculus can be useful when analysing remains that are considered to be sacred and that cannot be sampled using destructive methods, the authors note.

Am. J. Phys. Anthropol. http://doi. org/bdnb (2016)
VIROLOGY

\section{Zika's arrival in Americas tracked}

The Zika virus probably entered the Americas between May and December 2013, more than a year before it was first detected in Brazil.

A team led by Pedro Vasconcelos at Brazil's Ministry of Health in Ananindeua sequenced the genomes of seven Zika viruses isolated from patients and linked to the current outbreak of the disease in Brazil. They found little diversity among the viruses, indicating that they are all related to a single root virus that entered the country in 2013.

At that time, a growing number of passengers were arriving in Brazil by air from Zika-endemic areas such as the Pacific Islands, which experienced Zika outbreaks between 2012 and 2014. Science http://dx.doi.org/ 10.1126/science.aaf5036 (2016)

\section{$\rightarrow$ NATURE.COM}

For the latest research published by Naturevisit:

www.nature.com/latestresearch 